\title{
A Multi-Systems Life Course Perspective of Economic Abuse
}

\section{Kameri Christy Valandra}

\begin{abstract}
Intimate partner violence (IPV) against women slowly moved out of the private sphere and into the public realm in the United States in the early 1970's. While progress has been made regarding psychological, physical, and sexual trauma related to IPV, it has been only in the last decade that attention about IPV has included an examination of the impact of economic abuse (EA). This is disturbing given that EA is one of the eight spokes on the Power and Control wheel (PCW) and many women state that they are not able to leave or get away from the abusive relationship due to financial reasons. Using a multisystems life course (MSLC) perspective, this paper considers the importance of elevating EA as a form of IPV-related trauma. We examine EA's differential impact among women, review current practices and policies, and conclude with implications for micro, mezzo, and macro levels of trauma-informed practice with survivors of EA.
\end{abstract}

Keywords: Economic abuse; multi-systems life course; and culturally responsive practices

Violence and abuse against women by their current or former intimate partners slowly moved out of the private sphere and into the public realm as an issue for consideration in the United States in the early 1970's (McCue, 2007). At first, attention focused on physical abuse, with the addition of emotional and sexual abuse following at the end of the 1970's. It was not until 1993 that all 50 states criminalized marital rape (Bergen \& Barnhill, 2006). Much less attention has been given in the literature to an examination of economic abuse (EA; Adams, Sullivan, Bybee, \& Greeson, 2008; Postmus, Plummer, McMahon, Murshid $\&$ Kim, 2012). Furthermore, a 2014 national poll commissioned by the Allstate Foundation revealed that $78 \%$ of the public respondents had never heard the term economic abuse in relationship to intimate partner violence (IPV). While respondents believed economic abuse to be the least common type of IPV, the survey indicates that $99 \%$ of people "who have been victim of domestic violence have also experienced financial abuse" (Allstate Foundation, 2017, p.3).

The authors acknowledge that EA is not gender-restrictive since it can be experienced by both men and women. Nor is EA an exclusive form of IPV. Survivors often experience economic, physical, sexual, or emotional abuse simultaneously (Johnson, 2015). For the purposes of this article, the focus is on women survivors. Applying a multi-systems life course perspective (MSLC; Murphy-Erby, Christy-McMullin, Stauss, \& Schriver, 2010), we discuss the complexities of economic abuse and how it is experienced differentially by women. Lastly, we review current practices to address EA, and present micro, mezzo and macro practice implications to address EA from a MSLC perspective. To facilitate readability, a key of acronyms used in the article is included in the Table 1.

Kameri Christy, PhD, MSW, is Professor, School of Social Work, University of Arkansas, Fayetteville, AR 72701-1201. Valandra, PhD, MSW, MBA, LCSW is Assistant Professor, School of Social Work, and Director of African \& African American Studies, University of Arkansas, Fayetteville, AR 72701-1201 
Table 1. Acronyms

\begin{tabular}{l|l}
\hline EA & Economic Abuse \\
EAPCW & Economic Abuse Power and Control Wheel \\
FVO & Family Violence Option \\
IDA & Individual Development Accounts \\
IPV & Intimate Partner Violence \\
IPV-EA & Intimate Partner Violence and Economic Abuse \\
LGBT & Lesbian, Gay, Bi-sexual, Transgender \\
MAFM & Moving Ahead through Financial Management \\
MSLC & Multi-systems Life Course \\
PCW & Power and Control Wheel \\
REAP & Realizing Your Economic Action Plan \\
PRWORA & Personal Responsibility and Work Opportunity Reconciliation Act \\
TANF & Temporary Assistance for Needy Families \\
VAWA & Violence Against Women Act \\
\hline
\end{tabular}

\section{Understanding Economic Abuse and Its Impact}

While there is a paucity of scholarship on economic abuse, there has been an increase of publications on this topic since the early 2000's (see for example, Adams et al., 2008; Hahn \& Postmus, 2014). For this paper, the definition of EA provided by Adams and colleagues (2008) is used: "economic abuse involves behaviors that control a woman's ability to acquire, use, and maintain economic resources, thus threatening her economic security and potential for self-sufficiency (p. 564)." EA behaviors include preventing work outside the house, preventing ownership of personal possessions, preventing financial documents from being titled in a woman's name, preventing a woman's right to a bank account or other measures intended to prevent women from attaining monetary success (Domestic Abuse Intervention Programs, n.d.). EA may include such sabotage strategies such as physical harm, destruction of possessions or transportation, theft of keys or money, harassment at a woman's place of work, physical restraints, or other measures intended to harm a woman's chance of obtaining and/or maintaining gainful employment (Adams et al., 2008).

Economic abuse and socio-economic status are closely linked but are not synonymous. For example, we know that IPV is reported more among low-income women (Weaver, Sanders, Campbell \& Schnabel, 2009); however, women from seemingly moderate- and higher-income levels can experience economic abuse by a partner (Outlaw, 2009). EA is as prevalent as physical, psychological and sexual abuse, and is used by an intimate partner to gain control of a woman's life through economic means (Adams et al., 2008; Hahn \& Postmus, 2014). In a study comprised primarily of African American (48\%) and White $(45 \%)$ women $(\mathrm{N}=103)$ receiving IPV services, 99\% reported experiencing some type of economic abuse (Adams et al., 2008). Similarly, Postmus and colleagues (2012) found that 94\% of the 120 (55\% White, 20\% African American and 15\% Hispanic) female survivors of IPV reported economic abuse by their partner. In studies from the general public, 14\% of new mothers indicated they had been economically abused (Schrag, 2015). Outlaw (2009) found that the "risk of physical violence among those whose access to money was 
controlled by another was 4.68 times greater than for those not experiencing economic abuse" (p. 267).

\section{Conceptual Framework for Understanding Economic Abuse}

IPV is a complex and multifaceted phenomenon, with EA playing a central role. EA affects all aspects of life for individuals, families, communities, and society. For example, in the area of employment, over $\$ 8$ million paid workdays and $\$ 5.8-12.6$ billion are lost every year (National Coalition Against Domestic Violence [NCADV], 2015) due to such EA behaviors as harassment while on the job and absenteeism. We applied a MSLC perspective to address the complete context of EA.

MSLC is comprised of three theories and one perspective: (1) life course, (2) ecological/systems, and (3) symbolic interactionism theories, and a perspective of social change (Murphy-Erby et al., 2010). A MSLC perspective provides a way to unite the profession, expands and strengthens micro level practice through its consideration of macro level issues, and leads to the provision of more effective and efficient services. In this way, a MSLC perspective serves to address the historic tension between micro versus macro practice (Austin, Coombs \& Barr, 2008; Haynes, 1998). This integrative practice perspective views well-being and social change as interdependent (enhancing both social functioning and social conditions) and should be applied in all stages of practice such as engagement, assessment, intervention, and evaluation (Murphy-Erby et al., 2010).

Anchored in an intersectional perspective of multiple and overlapping social relations, ecological/systems theory posits that organisms exist within the context of multiple interrelated, dynamic systems (e.g., biological, political, and social). In other words, what happens in one realm impacts other realms, and these interactions occur bi-directionally (Bronfrenbrenner, 1989). The integration of symbolic interactionism into MSLC requires us to pay attention to the social construction of meanings, symbolism, and roles when considering the behaviors at the micro, mezzo and macro levels (Blumer, 1969). Life course theory asserts that historical, social, and political contexts influence the important turning points, transitions, and trajectories of organisms. The context is understood as the exchanges between internal free will and external forces (Elder, 1995). While the interaction between the person and environment is important, a social change perspective draws attention to the reality that free will may be constrained by powerful social forces. A social change perspective "adds an emphasis on the relationships among social justice, social change, and social action by considering issues of power and oppression and strategies for actively challenging the status quo to promote social change" (Murphy-Erby et al., 2010, p. 1).

Although there are overlapping themes between these theories and this perspective, each is needed to address gaps or limitations that exist in each of the other three. For example, life course theory does not speak to issues of power, privilege, or social action. Similarly, ecological/systems theory, while understanding contextual factors, fails to place strong emphasis on an in-depth analysis of time and place, or key historical events. Likewise, symbolic interactionism has been applied mostly to micro-level interventions; it has been underutilized regarding mezzo and macro-structures. Additionally, social change 
as a perspective allows a view of social movement and change that is often considered dichotomous, and minimizes the potential of individual empowerment. Therefore, MSLC is not used as four separate theories/perspectives but rather as an integrated whole whose intersecting concepts reinforce each other (Murphy-Erby et al., 2010). The overlapping aspects of the theories and perspective contained within MSLC demonstrate the concept of intersectionality as a perspective paradigm. In the same way that intersectionality attempts to understand multiple crucial, overlapping, and integrated systems of oppression experienced by an individual or larger system, MSLC asserts that individuals, groups, communities, and organizations with which social work intervenes are complex entities that cannot be wholly understood from one theoretic approach. MSLC integrates multiple theoretical frameworks, and thus is like an intersectionality perspective in its capacity to drive holistic examination and interpretation.

\section{Understanding EA from a MSLC Perspective}

Life course (Elder, 1995) and symbolic interactionism (Blumer, 1969) theories suggest an examination of EA relative to ascribed gender roles and life trajectories. The evolution of perceptions, policies, and practices pertaining to EA have been impacted by roles and meanings ascribed to men, women, marriage/intimate relationships, and money. Historically, the United States has supported a strong family ethic, "featuring a male breadwinner and an economically dependent female homemaker" (Abramovitz, 1996, p. 2). Along with this ethic is the presumption of men as strong, self-sufficient, head of the household and women as weak, dependent, less competent, and less intelligent than men. These beliefs unfortunately reinforce the concept of a husband-wife household where the man is all-knowing and makes all decisions, including the financial ones (Abramovitz, 1996). These meanings, compounded with a middle class, traditional life course perspective of women staying home to care for family members, sets the stage for certain behaviors to be overlooked and/or condoned. Consequently, it may be difficult for women and the rest of society to view behaviors such as taking (stealing) the woman's money, generating debt in her name, or forbidding her from going to school as economic abuse (Adams et al., 2008).

When a woman suffers in an environment of EA, the effects can extend far beyond her immediate situation. EA can affect both her life course and that of her children. The woman's employer may also feel impacts such as increased health expenses for the woman and her children, as well as decreased employee productivity. Furthermore, the economic health of the greater society can be affected by the woman's curtailed participation in the workforce (Trygged, Hedlund, \& Käreholt, 2014). Given the ubiquitous nature of EA, addressing it will involve cultural change at the individual, community, and societal level.

Drawing upon symbolic interactionism, ecological/systems theories, and a social change perspective, prevention and intervention require collaboration among systems/groups and a shift in the meaning our culture ascribes to such concepts as money, family (Hawkins \& Kim, 2012), gender roles/expectations, and IPV. Within a social change perspective, the act of ascribing meaning to those concepts is informed by a consideration of issues of power, privilege, and inclusion. Such consideration is required 
to reveal the existence of EA and to unveil the secrets behind who benefits and who loses from the current economic system and EA.

An analysis of how the gender pay-gap provides a contextualized examination of women's vulnerability to EA by an intimate partner using the MSLC perspective will help illustrate the above assertions. The difference between what women make in the workforce compared to men can be attributed to macro, mezzo, and micro factors. The persistent existence of a gender wage-gap can be understood, in part, by overarching intersectional ideologies of patriarchy, heterosexual marriage and the nuclear family, and capitalism. These prevailing ideologies are influential in the development of a system of social control and paternalism regarding the subjugation of women's labor, reproduction, and right to self-determination (Day \& Schiele, 2012). The National Women's Law Center (2016) indicates that some of the reasons include lack of laws requiring equal pay for equal work, negative stereotypes about mothers and women being discouraged from entering better paying fields. Research has also shown that IPV is correlated with lower pay (Adams et. al, 2008). Therefore, it can be convincingly argued that historical and systemic structures of gendered income inequality, inaccessibility to viable wage-earning resources (employment, education, affordable daycare, etc.), and socially accepted and perpetuated gender-based cultural norms and laws, in effect, exacerbate women's susceptibility to economic deprivation and EA by an intimate partner.

The $21 \%$ difference in the pay women receive compared to men (American Association of University Women, 2016) has multiple ramifications. While distressing, reporting the wage gap at $21 \%$ is misleading. Compared to White, heterosexual, cisgendered, fathers and older men, the disparity is often more egregious with pay differences of $40 \%$ for African American women, $45 \%$ for Latina, $21 \%$ for lesbians, $33 \%$ for transgendered women, 27\% for mothers and 27\% for women ages 45-64 (National Women's Law Center, 2016). Additionally, women living with disabilities earn on average $28 \%$ less than men living with disabilities (National Women's Law Center, 2016).

Lower wages mean less income for not only the woman but for the entire household (systems theory). Whether a single head of household or a dual-income household, fewer financial resources can limit the ability to pay bills and purchase adequate food and shelter (Mickelson \& Hazlett, 2014; Page-Reeves, 2011). Economic hardship is also associated with financial reliance on men and the inability of women to leave an abusive relationship (Abramovitz, 1996; Sanders, 2015).

Critiquing consequences of the wage gap from a MSLC perspective, children, families, local communities (including schools), and the national budget are disadvantaged in a selfperpetuating cycle of EA of women, leading to economic hardship for the woman and her children, which in turn can lead to economic vulnerability and EA for children when they become adults. Some long-term effects include poorer public education for the children, which often results in low graduation rates and low rates of post-secondary education/training (Hawkins \& Kim, 2012). Inadequate educational facilities and experiences can cause students to devalue education and themselves (Purtell \& McLoyd, 2013). They may believe that the roles ascribed to their financially struggling parent(s) will be the same that they will bear as adults (Purtell \& McLoyd, 2013). This belief is an 
outgrowth of economic insecurity and is often realized as children grow up to find themselves doing low-wage work as adults and at risk for EA from an intimate partner. Incarceration is also linked to children's expectation that their roles in adulthood will mirror those of their financially struggling parents (Purtell \& McLoyd, 2013).

\section{Women's Differential Experiences of EA from a MSLC Perspective}

MSLC demands of practitioners a critical and contextual analysis of the intersectional complexity of EA to better serve the diverse needs of survivors and to advocate for systems change. A MSLC wage-gap analysis serves as a means of understanding how the intersections of culture, class, race, and ethnicity differentially magnify women's experiences of IPV-EA (see Figure 1; Bent-Goodley, 2005; Rennison \& Planty, 2003; Sokoloff \& Dupont, 2005). Previously articulated pay disparities experienced by women of color and poor, lesbian, and older women (National Women's Law Center, 2016) suggest that some women are also vulnerable to intersectional structures of race, class, sexual orientation, and age inequality that can exacerbate their vulnerability of IPV-EA by partners (Bent-Goodley, 2005; Sokoloff \& Dupont, 2005).

The historical context of enslavement and colonization, for example, is acknowledged in IPV-related scholarship as critical to understanding the needs of both survivors and men of color who commit violence and to providing culturally-sensitive services (Gondolf \& Williams, 2001; McEachern, VanWinkle, \& Steiner, 1998). In the United States, the legacy of slavery and colonization has resulted in longstanding structural income inequality, economic oppression, and negative stereotypes in which women of color are disproportionately represented as a high-risk group for EA (Rennison \& Planty, 2003; Valandra, Murphy-Erby, Higgins, \& Brown, 2016). Brush (2004) notes that in the United States women of color are disproportionately represented among recipients of public welfare, a context in which poverty, welfare, work, and vulnerability to IPV and EA intersect.

The disproportionate representation of women of color in the low-income sector of society increases their vulnerability to structural conditions of race-, class-, and genderbased discrimination limiting their accessibility to formal economic resources and increasing the likelihood of experiences of generational poverty (Corcoran, 1995). In a study examining EA survivors' use of informal economic resources, Pyles (2006) found that poor, incarcerated women, who were disproportionately African American/Black and Latina/Hispanic, more frequently relied on money and gifts from family, payday loan services, pawning items, selling blood or plasma, and illegal informal activities such as writing bad checks, while White women were more likely to use credit cards to access resources. The findings from these studies illustrate the importance of using an MSLC perspective to illuminate the links between the structural context of economic marginalization and exploitation and its intersections with interpersonal EA in the lives of women of color living in poverty (Sokoloff \& Dupont, 2005).

An MSLC analysis of EA in the lives of poor women of color alerts scholars and practitioners to recognize the ways in which oppressive structures such as patriarchy and poverty shape cultural contexts and impact the incidence of IPV-EA and its economic 
consequences in marginalized communities. Within this context, symbols of safety (police authorities, criminal justice) in one community can be experienced as symbols of oppression in another and result in barriers to service utilization (Campbell et al., 2008; Renzetti, 1998; Sokoloff \& Dupont, 2005). For example, in an examination of cultural context in the experiences of African American women IPV survivors, researchers found that women's concerns about further economic strife in their families associated with the possible incarceration of male abusive partners influenced their decisions regarding whether to report violence to police authorities (Campbell et al., 2008). The symbolism and meaning women of color give to the systematic incarceration of men of color has significant implications for addressing EA through culturally responsive, oppression sensitive practice. The application of the MSLC perspective, thus, also entails a critical assessment of how service delivery systems intended to support survivors of EA and violence may be structured in ways that perpetuate cultural barriers, stereotypes, and discriminatory treatment of women of color (Valandra, 2007; West, 1999).

Ten different tactics of abuse, including EA, were found in a study investigating how particular structural-, cultural-, and community-level factors, influenced specific abuse tactics experienced by 29 Mexican immigrant women recruited from two geographically diverse sites (Kyriakaskis, Dawson, \& Edmond, 2012). The abuse tactics employed by husbands were inextricably linked with cultural expectations of married Mexican women and reflected patriarchal expectations of women in Mexico (Kyriakakis et al., 2012). EA in this study consisted of economic deprivation, the prevention of women from working, taking women's paychecks, and allotting them allowances. Consistent with MSLC's emphasis on social change, domestic violence researchers who promote the examination of the intersections of structural and interpersonal factors on women's experiences of IPV and EA also argue for the importance of interventions that not only address women's specific needs, but also challenge cultural and structural conditions that can fuel EA (Sokoloff \& Dupont, 2005).

\section{Critiquing Current Practice Interventions from an MCLS Perspective}

Literature on EA in the United States is sparse; however, a few articles do discuss direct and policy practice interventions. Most of the current interventions involve the (1) use of the Power and Control Wheel (PCW; Christy-McMullin, 2011), (2) provision of financial literacy and empowerment education, with emphasis on the applicability (Hahn \& Postmus, 2014), and (3) use of Individual Development Accounts (IDAs) developed specifically for survivors of EA (see Table 2 for a summary of recommendations for each intervention; Hahn \& Postmus, 2014). 
Figure 1. MSLC Analysis of Wage-Gap Influence on EA Risk

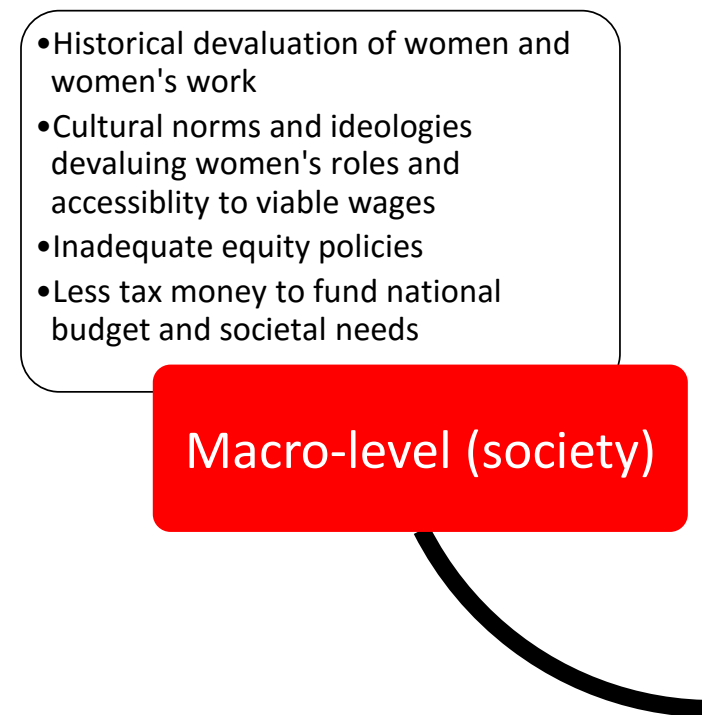

- Poor community resources

- Lower tax revenue

- Inadequate public education funding and

quality

- Unemployment and underemployment

- Economic vulnerability

-Increased vulnerabilty to EA

- Low graduation rates

- Low educational outcomes

- Generational poverty

- Poverty in retirement

-Inability to pay bills

- Lower wages

- Incarceration

-Increased stress, health problems

-Premature, preventable death

\section{Micro-level (woman} and children) 


\section{Power and Control Wheel}

Developed in the mid-1980's, the PCW intervention tool explicitly identifies eight abusive strategies employed within a context of a larger system of abuse (Domestic Abuse Intervention Programs, 2011). The abusive tactics identified on the PCW include using (1) intimidation, (2) emotional abuse (3) isolation, (4) minimizing, denying and blaming (5) threatening to take children, using them to relay messages, (6) male privilege, (7) economic abuse and (8) coercion and threats (Domestic Abuse Intervention Programs, 2011). The PCW is based on data collected from female survivors over several months and has been translated into more than 40 languages (Domestic Abuse Intervention Programs, 2011). The PCW allows practitioners to help clients determine, and sometimes come to terms with their situation, while also clearly defining abuse as a way that an abuser attempts to control or limit the victim. It can be useful in helping survivors break through a pattern of denial and minimization about abusive patterns of behaviors (Christy-McMullin, 2011). EA is clearly identified as one of the eight strategies listed in the PCW's larger system of abuse (Domestic Abuse Intervention Programs, 2011). Since the creation of the original PCW, numerous other wheels have been adapted in recognition that women's social location in relation to the environmental context influences their experiences and responses to EA such as the Equality Wheel (Domestic Abuse Intervention Programs, 2011), Lesbian Gay Bisexual Transgender (LGBT) Wheel (NW Network, n.d.), Teen Dating Violence Wheel (National Center on Domestic and Sexual Violence, 2017) and Economic Abuse Power and Control Wheel (EAPCW; Arizona Coalition to End Sexual and Domestic Violence, n.d.).

Like its predecessor, the EAPCW has eight categories of abuse operationalized; (1) legal issues, (2) employment and workplace, (3) finances and credit, (4) child support, (5) welfare, (6) housing, (7) child care, and (8) education and training (Arizona Coalition to End Sexual and Domestic Violence, n.d.). As with the original, the EAPCW can be used to help allies, survivors, and offenders to better understand the tactics of EA.

The prevalence of utilization and the development of other PCWs suggest it is an effective intervention. However, the authors could not find research to support this assumption. Nevertheless, it is worthwhile to analyze the EAPCW from a MSLC perspective to potentially expand the interventions that are used with it. 
Table 2. Practice Recommendations Relevant to Economic Abuse

\begin{tabular}{|c|c|c|}
\hline & MSLC Application & Practice Implications \\
\hline $\begin{array}{l}\text { Power \& } \\
\text { Control } \\
\text { Wheel }\end{array}$ & $\begin{array}{l}\text { 1. Consider the historical/political/ social } \\
\text { context of IPV-EA } \\
\text { 2. Recognize meanings, values and assumption } \\
\text { around EA, finances and women's roles } \\
\text { 3. Assess impact of current life trajectory on } \\
\text { self and others } \\
\text { 4. Acknowledge and work with the many } \\
\text { systems involved and impacted by EA }\end{array}$ & $\begin{array}{l}\text { 1. Use the EAPCW along with PCW } \\
\text { 2. Provide client-centered training on EA and the EAPCW } \\
\text { 3. Use cognitive-behavioral therapy to challenge woman's sense of self- } \\
\text { agency; make explicit the role of culture, privilege and oppression } \\
\text { 4. Discuss trajectory of the woman, her children and family } \\
\text { 5. Work with various systems to bring about social change } \\
\text { 6. Develop appropriate system for timely referrals }\end{array}$ \\
\hline $\begin{array}{l}\text { Financial } \\
\text { Literacy } \\
\text { Education }\end{array}$ & $\begin{array}{l}\text { 1. Consider the historical/political/ social } \\
\text { context of finances, work and women } \\
\text { 2. Recognize meanings, values and assumptions } \\
\text { around EA, finances and women's roles } \\
\text { 3. Assess impact of current life trajectory on } \\
\text { self and others } \\
\text { 4. Acknowledge and work with the many } \\
\text { systems involved with and impacted by EA } \\
\text { and the lack of financial literacy }\end{array}$ & $\begin{array}{l}\text { 1. Adequately fund programs specifically for survivors of IPV-EA, e.g., } \\
\text { REAP and MAFM } \\
\text { 2. Change perceptions and expectations around finances and women } \\
\text { 3. Provide financial literacy education to frontline workers } \\
\text { 4. Engage multiple systems, e.g. workplace or religious community, in } \\
\text { providing financial literacy education } \\
\text { 5. Train frontline workers on how to present culturally relevant financial } \\
\text { literacy education to their customers } \\
\text { 6. Advocate for social and economic justice reforms that affect conditions of } \\
\text { 7. Coverty, racism, sexism, and homophobia }\end{array}$ \\
\hline $\begin{array}{l}\text { Financial } \\
\text { Asset } \\
\text { Building }\end{array}$ & $\begin{array}{l}\text { 1. Consider the historical/political/ social } \\
\text { context of assets and IPV } \\
\text { 2. Recognize meanings, values and assumptions } \\
\text { around EA, financial assistance, economic } \\
\text { security and assets } \\
\text { 3. Assess impact of asset accumulation on the } \\
\text { trajectory on self and others } \\
\text { 4. Acknowledge and work with the many } \\
\text { systems involved with and impacted by EA } \\
\text { and assets }\end{array}$ & $\begin{array}{l}\text { 1. Adequately fund IDA programs for survivors of IPV-EA with VAWA } \\
\text { funding } \\
\text { 2. Change perceptions and expectations around financial assistance and EA } \\
\text { 3. Provide EA training to IDA providers/administrators to create culturally } \\
\text { relevant programming to their customers } \\
\text { 4. Advocate for social and economic justice reforms } \\
\text { 5. Conduct oversight and evaluation of IDA program implementation }\end{array}$ \\
\hline
\end{tabular}


A first step would be for direct practice practitioners to specifically use the EAPCW instead of relying solely on the original PCW. While using this wheel, practitioners can explore the historical context of financial knowledge, decision-making processes and resources, IPV and EA, along with the meaning made of these concepts by the women, their families of origin, their current family structure, members of the larger community, and their hopes for the future. Further application of MSLC is an assessment of the family's life course trajectory to understand the specific manifestations of EA within the family system. Making explicit the role of culture and ascribed meaning should also include a discussion of how the woman perceives herself and her self-agency. With this, practitioners should be aware of and introduce such concepts as privilege and oppression. Intermingled within this assessment should be conversations about how different systems have been and may be impacted in the future given the status quo, as well as the systems that can provide support and resources to the woman, her children, and her partner. It is not enough to merely understand this impact, but social workers using MSLC would also consider interventions that change the status quo.

To better explicate the application of a MSLC perspective, we will take one of the tactics from the EAPCW, 'Employment and Workplace,' (Arizona Coalition to End Sexual and Domestic Violence, n.d.). to provide more specific examples of assessment and interventions. We must consider not only the many systems (e.g, legal, state agencies, employers, religious, and/or family) impinging upon the woman, but the meanings and values held by the woman, her family, and various systems. Some of the negative assumptions might include: women should not be in the workforce; women are not as reliable in the workforce as men; poor women and women of color are lazy and do not want to work; staying home to take care of others is not really work particularly when talking about women of color and low-income women because middle- and upper-income and white women have been allowed, even encouraged to work in the home; women enjoy/deserve abusive relationships; women can leave the abusive relationship if they so choose and if a woman left her abusive partner the abuse would stop. Assessing the different meanings and values held can shape how much or little power/influence each of the various systems has on the woman across her work life. While these various systems may not always agree, some may have more power/influence. For example, lawmakers have the power to support or oppose laws that provide more employment resources and support for women who are experiencing EA, and laws mandating equal pay for women and increasing the minimum wage. Regardless of public policy on these issues, employers have the ability to incorporate these policies into their organizations. The status quo benefits those who hire women at a lower wage rate; however, not addressing economic abuse, women are less able to be productive due to EA, which costs the employer more money.

Interfering with the work trajectory of a woman has severe consequences in the present for herself (e.g., stress, health problems, inability to pay bills and homelessness), her children (e.g., lack of access to a good education and educational materials), and society (she will be paying less into the tax system). Her future (e.g., poverty in retirement) and those of her children (limited educational and employment as adults) and society (less money paid in taxes results in less public revenue) can be negatively impacted as well. 
Hahn and Postmus (2014) noted that women often feel ostracized from using social services because workers are untrained in how to work with women experiencing IPV. From a MSLC perspective, client-centered training regarding survivors of abuse is a necessity in state agencies like the Division of Children and Family Services that see IPV on the frontline most often. One intervention could be to standardize the use of the PCW and EAPCW. These wheels provide enough examples of abusive behaviors and control tactics used by abusers that they can be used and adapted by advocates. Additionally, therapists using cognitive-behavioral therapy can use the wheels to facilitate a better identification of behaviors and understanding of the client's thoughts and feelings about those behaviors and an avenue to reframe labels and stigma (symbolic interactionism). Furthermore, the EAPCW can be used to assess the depth of economic abuse and can be highly useful for practice with EA survivors in (1) helping them understand key tactics used to keep women in abusive relationships (social change), (2) helping them develop strategies to address financial needs (systems) and (3) pointing to potential goals a woman might want to set for herself (life course). The EAPCW can also be used to train service providers and to increase public awareness of EA (Christy-McMullin, 2011), whereby a system of referral (thereby changing the status quo) could be designed and used to provide connections to culturally appropriate services in an improved period.

\section{Financial Education and Literacy}

The purpose of financial education is to increase one's financial literacy, which is "the ability to discern financial choices, discuss money and financial issues without (or despite) discomfort, plan for the future, and respond competently to life events that affect everyday financial decisions" (Vitt et al., 2000, p. xii). The U.S. Department of Treasury, Social Security Administration, and Obama administration showed an understanding of the interconnection between financial literacy and IPV for girls/women (Gjertson, 2011). However, it is important to move beyond traditional perceptions that financial literacy education alone will change behaviors/outcomes (Hawkins \& Kim, 2012). Knowledge alone may not change behavior/outcomes and focusing on financial literacy education as a solution has the potential to victim-blame by implying that "financial literacy alone can produce long-term change in consumer financial markets and absolve public and private entities of their responsibilities" (Hawkins \& Kim, 2012, p. 194). Therefore, changing structural barriers, such as low-paying jobs, lack of high quality childcare (Fine \& Weis, 2000) and lack of safe, affordable housing should go hand-in-hand with financial literacy education.

Turning first to financial literacy education, as demonstrated by a 2014 study conducted by the World Bank, Gallup, and George Washington University, almost half of the U.S. adult population (43\%) is financially illiterate (McGrath, 2015). Further, only 52\% of women in the U.S. are financially literate, compared to $62 \%$ of men (Standard \& Poor, 2015). Without economic empowerment (financial knowledge and skills), women suffering from EA may experience less economic self-efficacy and face more challenges in becoming financially self-sufficient (Adams et al., 2008). Given that economic dependence on their partner is one of the main reasons women remain in abusive 
relationships (Sanders, 2011), providing programs that increase women's financial literacy may increase economic self-efficacy (Hahn \& Postmus, 2014).

REAP and MAFM literacy programs. Two research-supported financial literacy and economic empowerment education courses described by Hahn and Postmus (2014) are "Realizing Your Economic Action Plan," (REAP) and "Moving Ahead through Financial Management" (MAFM). Both are designed to empower women before, during and after the process of acknowledging EA in their relationship, and potentially leaving an abusive relationship. The programs seek to educate in such a way that women who are afraid to leave abusive relationships because of limited financial resources, employability, and economic prospects learn the steps to take to strengthen their financial competency, making an escape from an abusive relationship more possible (Hahn \& Postmus, 2014).

To do this, REAP has developed a 12-hour curriculum across five economic facets. These facets are: (1) money and power, (2) developing a cost-of-living plan, (3) building and repairing credit, (4) banking and investing, and (5) oppression and economic abuse. Hahn and Postmus (2014) found that women in the REAP group had statistically significantly higher scores on financial self-efficacy than did the control group. Additionally, the program respondents reported they had learned new financial knowledge from the classes.

A collaborative effort, Allstate Foundation and the National Network to End Domestic Violence created the MAFM program (Hahn \& Postmus, 2014). Its curriculum focuses on: (1) economic abuse and relationships, (2) financial fundamentals, (3) building a financial base, (4) creating long-term financial success, and (5) financial strategies for immigrant and refugee women (Hahn \& Postmus, 2014). A pre-test/post-test non-experimental design was used and findings indicate significant increases in women's financial literacy, economic empowerment, economic self-sufficiency, and economic self-efficacy. Additionally, $88 \%$ of participants could clearly identify signs of economic abuse, $88 \%$ had developed financial goals after the course, $76 \%$ had developed a budget, $71 \%$ had taken steps to start paying off debt, $64 \%$ had accessed records of their credit history, and $22 \%$ started a retirement account. In-depth analysis showed that participants' heightened levels of financial literacy and economic self-efficacy predicted economic empowerment (Hahn \& Postmus, 2014).

Applying a MSLC perspective to financial literacy of women who experience EA involves an assessment of symbols; traditions; life trajectories; historic, social, and political contexts; diversity and culture; systems and resources, as well as a call for social change. As discussed previously, women are less likely to be financially literate than men. This may be in part such symbolism as men being the "head" of the household and/or the "primary breadwinner," as well as an assumption that men should make the financial decisions in the family. As for low-income individuals and families, public misperceptions that low-income families do not need financial education may contribute to the $17 \%$ gap in financial literacy between the wealthiest $60 \%$ and poorest $40 \%$ of households in the U.S. (Standard \& Poor, 2015). Changing these perceptions and expectations is critical because financial literacy "shapes the life course in other, extended ways by enhancing access to investment income, asset accumulation and asset protection" (Vitt et al., 2000, p. xiii) for 
women and their children. Additionally, it must be recognized that the type of information needed regarding finances changes over the course of people's lives to assist with transitions and life trajectories.

Two federal policies created to specifically address IPV are Violence against Women Act of 1994 (VAWA) and an amendment to the Personal Responsibility and Work Opportunity Reconciliation Act (PRWORA) of 1996, The Family Violence Option (FVO) of 1996. One intention of VAWA was to create opportunities for economic empowerment for women surviving IPV by allocating funds for services and further research to determine appropriate practices for intervention. However, according to Hahn and Postmus (2014), VAWA has largely failed in that regard, with limited rental housing opportunities being the only services consistently funded by the legislation and focus instead being largely shifted to criminalization of abusers. Johnson (2015) argues it has led to a focus on safety (short-term goal) rather than security (long-term goal). Similarly, the explicit goals of the Family Violence Option (FVO), (1) screening for intimate partner violence, (2) providing appropriate referrals in cases of IPV and (3) waiving time limits and work requirements of women experiencing IPV, are not being met (Lindhorst \& Padgett, 2005).

The FVO and VAWA are examples of policies that could be augmented to provide specialized, culturally responsive services to economically empower women who experience EA. Department of Children and Family Services (DCFS) workers are oftentimes the front-line for IPV intervention. However, they often the lack knowledge of or ability to uniformly implement this policy, which results in the services, waivers and extensions allowed by the policy not being provided to eligible recipients (An, Yoo, \& Nackerud, 2015). Advocacy and promotion of the FVO as required national policy is needed to promote an effective and consistent system of implementation for the FVO. In addition to changing the FVO from an optional to a required policy, it will be important that (1) state workers receive ongoing training, (2) accountable oversight of the policy's implementation is established and maintained, and (3) regular evaluation of the implementation of the FVO occurs. The on-going culturally-responsive training of state workers would especially benefit poor and women of color who are largely represented among service recipients of state welfare programs and EA.

Additionally, culturally-responsive financial literacy training for frontline community and state workers will enable them to provide specific case management services for women who want to leave abusive relationships, but do not have sufficient economic prospects such as employability, access to financial education, stable credit, or other assistance options. Workers need to learn how to identify EA correctly and understand general mechanics of it, allowing for the development of a system of referral that can be used to provide connection to culturally-appropriate services in an improved timeframe. The training should also include content on how to advocate for social and economic justice reforms within the system that affect conditions of poverty, racism, sexism, and homophobia (Christy-McMullin, 2011; Coker, 2000; Richie \& Kanuha, 1993). In order to provide resources that will enhance individual women's economic empowerment, workers need to receive financial literacy education training. This will increase both their own financial literacy and provide them with firsthand knowledge of issues clients may face (Christy-McMullin, 2011). 
Other systems, such as workplaces, could help increase the financial literacy of the public by offering financial literacy training. The workplace is a good location for many individuals, with the rewards being "mutually beneficial for both employer and employee. We urge many more employers to offer personal finance courses... and we support public policy initiatives that offer incentives to those employers who do" (Vitt et al., 2000, p. xvii). Other systems, such as faith-based or community organizations (Vitt et al., 2000) can be important resources in providing financial education. Another useful strategy would be to target specific populations for financial literacy education. One example is domestic violence agencies since women who access them "are one of the many groups that could benefit substantially from financial education programs, especially those that meet their unique needs by providing content on economic abuse and economic safety plans" (Postmus, p. 1, 2011). As noted by Sanders, "low-income women [also] face significant challenges to building financial security, as they often lack resources, knowledge, and access to financial services" $(2011$, p. 1$)$.

\section{Developing Financial Assets}

Historically, researchers have equated economic security with employment and/or income (Christy-McMullin, 2002). However, in the past 30 years, some scholars have begun to advocate for the importance of including financial assets in our definition of economic security (Johnson, 2015; Sherraden, 1988). In a review of the literature, PageAdams and Sherraden (1997) found financial assets have a positive relationship with psychological well-being, physical health, life satisfaction, and child well-being. They also report a negative correlation between assets and economic strain, alcoholism, and depression. While there have been few studies to examine the relationship between asset ownership and IPV (Hahn \& Postmus, 2014; Sanders, 2014), two studies indicate a negative relationship between owning a home and IPV (Christy-McMullin \& Shobe, 2007; Peterson, 1980).

In his groundbreaking book, Assets and the Poor, Sherraden (1991) proposed a change in policy that would create Individual Development Accounts (IDAs) to assist low-income workers with building financial assets. His rationale, in part, is that the United States has a long history of upper- and middle-income earners benefiting from a redistribution of public funds to support their asset-building activities, such as homeownership and retirement accounts. However, public support for providing similar help to low-wage earners has been slow (Murphy-Erby, Jordan, Shobe \& Christy-McMullin, 2009). Opponents of IDAs typically espouse the beliefs that low-income workers are poor due to their inability or unwillingness to manage their money properly (Murphy-Erby et al., 2009). Consequently, while most are not concerned with significantly more public funds going to middle- and upper- income earners, as well as large corporations, the same support for subsidizing lowwage earners is minimal (Christy-McMullin, 2000). One of the goals of IDA policy is to provide more social and economic justice to the working poor (Murphy-Erby et al., 2009).

Publically subsidized IDAs were first created through the Assets for Independence Act (AFIA) of 1998, and are designed to help low-income persons attain and maintain assets to develop a long-term sense of economic well-being (Hahn \& Postmus, 2014). Most programs also offer a financial literacy component. Many states have implemented IDAs 
using "savings" from their Temporary Assistance for Needy Families (TANF) funds. During the first 10 years of AFIA, over 600 IDA programs have been funded, with more than 60,000 IDAs opened nation-wide. IDAs use a match-ratio to match contributions made by account holders, up to $\$ 20,000$ yearly in some states (Hahn \& Postmus, 2014).

IDA programs have the potential to counteract the tactic used by abusive partners to "isolate women from financial resources and engage in antics that prevent women from gaining economic independence" (Sanders, 2011, p. 1). Additionally, asset accumulation may (1) decrease a woman's vulnerability to IPV-EA and (2) provide a woman more options if she experiences IPV (Christy-McMullin, 2000; Johnson, 2015; Sanders, 2011).

Asset-building programs, such as IDAs, have been minimally used in the field of IPV to help empower impoverished survivors of EA (Hahn \& Postmus, 2014). While little research has been conducted on the success of IDAs for IPV survivors (Hahn \& Postmus, 2014), Sanders and Schabel (2008) found that in less than four years, 75 participants saved, on average, $\$ 845$. Each woman received a match of approximately $\$ 1,573$. They were able to use their funds to pay for such assets as (1) vehicles and registration, (2) post-secondary education, (3) home repair and (4) home purchase. In a later study of 125 IPV survivors, Sanders (2014) found that IDA participants saved on average $\$ 1,310$ (median $\$ 1,500$ ) over a 2.5-year period. Coupled with the matched deposits and earned interest, the women had an average savings of $\$ 3,041$ and a median savings of $\$ 4,394$. As with the PCW and financial literacy education, application of MSLC to asset development is complex and comprehensive. Attitudes about welfare and financial assets need to be challenged at multiple levels; individual, family, community, and government. While most of the public understand that welfare is the transfer of public funds from one group to another, a large segment do not understand that policies such as tax breaks and deferments are not only welfare, but also that the majority of these transfers go to middle- and upper-income workers and large corporations (Sherraden, 1991).

Proponents of multicultural interventions to address IPV and EA argue that policy reforms must be tailored to the diverse needs of marginalized women whose experiences of EA are often exacerbated by structural economic and social conditions and inequities (Dasgupta, 1998; Richie, 2000). Expanding the number of IDA programs of survivors of IPV-EA, and having them administered by staff with training in IPV-EA, would help remedy some of these conditions and inequities. To do this, modifying VAWA (1994) to include administrative and evaluation costs, as well as matched funds for IPV IDAs has the potential to increase the number of IDA programs designed specifically for survivors of IPV-EA. Along with increased funding, policymakers and practitioners need to be aware of cultural issues that may exist when women attempt to save money for themselves. For example, money and property may not be viewed as belonging to an individual or family, but rather to the community (Hawkins \& Kim, 2012). Consequently, joining an IDA program in which individuals save money for themselves to purchase an asset for themselves may be viewed as disrespecting cultural norms. Such individuals may experience pressure to share their money rather than depositing it in an IDA (Hawkins \& Kim, 2012). Allowing community-held assets as an approved use of money from an IDA may be one solution to this conundrum (Jorgensen \& Morris, 2010). Additionally, women experiencing EA often have financial needs beyond the approved purchases of home or 
business ownership, such as transportation, quality childcare, healthcare (Johnson, 2015), and/or hiring a lawyer. Restricting allowable purchases only reinforces patriarchal assumptions that women are not able to make good decisions on their own (Johnson, 2015).

\section{Conclusion}

The use of a MSLC perspective to illuminate the importance of EA as a significant form of IPV-related trauma offers social workers an integrated, multidimensional approach of assessing, intervening, and preventing EA across all systems of direct, policy, and social justice practice. Additionally, specific strategies for addressing EA-specific IPV can be more effectively tailored to meet the diverse and intersecting needs of women based on their differential experiences relative to their sociocultural identity within the larger community and society as well as the specifics of their family life course trajectory. Additionally, a MSLC lens facilitates the use of the EAPCW as a more effective assessment and intervention tool for practice with survivors, offenders, and secondary EA trauma survivors as well as a training tool for practitioners providing services across all systems of practice. Social workers should consider the complexity and interplay of power, privilege, and oppression within the context and roles of historical, cultural, and societal structures, norms, and scripts that place women at risk for EA. As such, social workers are better equipped to provide integrative, culturally inclusive, oppression-sensitive EA services that meet the needs of multiple levels of the practice landscape including direct practice, policy advocacy, community development, and structural systems change.

\section{References}

Abramovitz, M. (1996). Regulating the lives of women: Social welfare policy form colonial times to the present. Boston: South End Press.

Adams, A. E., Sullivan, C. M., Bybee, D., \& Greeson, M. R. (2008). Development of the Scale of Economic Abuse. Violence Against Women, 14(5), 563-588. doi: https://doi.org/10.1177/1077801208315529

Allstate Foundation. (2017). "Get the Facts: Statistics." Available at http://purplepurse.com/get-the-facts/about-domestic-violence/statistics

American Association of University Women. (2016). The simple truth gender pay gap. Retrieved from https://www.aauw.org/files/2016/02/SimpleTruth_Spring2016.pdf

An, S., Yoo, J., \& Nackerud, L. G. (2016). Using Game Theory to Understand Screening for Domestic Violence Under the TANF Family Violence Option. Advances in Social Work, 16(2), 338-357. http://dx.doi.org/10.18060/16671

Arizona Coalition to End Sexual and Domestic Violence. (n.d.). Economic abuse wheel. Available at http://www.azcadv.org/azcadv2014wp/wpcontent/uploads/2016/12/Economic-Abuse-Wheel.pdf

Assets for Independence Act of 1998, 42 U.S.C. 604 Retrieved from https://www.acf.hhs.gov/ocs/resource/afi-legislation-0 
Austin, M. J., Coombs, M., \& Barr, B. (2008). Community-centered clinical practice: Is the integration of micro and macro social work practice possible? Journal of Community Practice, 13(4), 9-30. doi: https://doi.org/10.1300/J125v13n04_02

Bent-Goodley, T. (2005). Culture and domestic violence: Transforming knowledge development. Journal of Interpersonal Violence, 20, 195-203. doi: https://doi.org/10.1177/0886260504269050

Bergen, R. K., \& Barnhill, E. (2006). Marital rape: New research and directions. National Resource Center on Domestic Violence. Available at: http://vawnet.org/sites/default/files/materials/files/201609/AR_MaritalRapeRevised.pdf

Blumer, I-I. (1969). Symbolic interactionism: Perspective and method. Englewood Cliffs, NJ: Prentice-Hall.

Bronfenbrenner, U. (1989). Ecological systems theory. Annals of Child Development, 6, 187-249.

Brush, L. D. (2004). Battering and the poverty trap. Journal of Poverty, 8(3), 23-43. doi: https://doi.org/10.1300/J134v08n03_02

Campbell, J., Campbell, D. W., Gary, F., Nedd, D., Price-Lea, P., Sharps, P.W., \& Smith, C. (2008). African American women's responses to intimate partner violence: An examination of cultural context. Journal of Aggression, Maltreatment \& Trauma, 16(3), 277-295. doi: https://doi.org/10.1080/10926770801925684

Christy-McMullin, K. (2000). An analysis of the Assets for Independence Act of 1998 for abused women. Violence Against Women, 6(10), 1066-1084. doi: https://doi.org/10.1177/10778010022183523

Christy-McMullin, K. (2002). Designing policies that address the relationship between woman abuse and economic resources. Journal of Sociology and Social Welfare, 24(3), 109-124.

Christy-McMullin, K., \& Shobe, M. A. (2007). The role of economic resources and human capital with woman abuse. Journal of Policy Practice, 6(1), 3-26. doi: https://doi.org/10.1300/J508v06n01_02

Christy-McMullin, K. (2011). Building the capacity of human service providers to deliver financial literacy to domestic violence survivors. Center for Financial Security, University of Wisconsin. CFS Research Brief 2011-5.5.

Coker, D. (2000). Shifting power for battered women: Law, material resources, and poor women of color. University of California Davis Law Review, 33, 1009-1055.

Corcoran, M. (1995). Rags to rags: Poverty and mobility in the United States. Annual Review of Sociology, 21, 237-267. doi: https://doi.org/10.1146/annurev.so.21.080195.001321

Dasgupta, S. D. (1998). Women's realities: Defining violence against women by immigration, race and class. In R.K. Bergen (Ed.), Issues of intimate violence (pp. 
209-219). Thousand Oaks, CA: Sage. doi:

https://doi.org/10.4135/9781483328348.n14

Day, P. J., \& Schiele, J. (2012). A new history of social welfare: Connecting core competencies (7th ed.). Boston, MA: Pearson Education.

Domestic Abuse Intervention Programs. (2011.). The Duluth Model Wheel gallery. Available at http://www.theduluthmodel.org/training/wheels.html

Elder, G. H. Jr. (1995). The life course paradigm: Social change and individual development. In P. Moen, G. H. Elder, \& K. Luscher (Eds.), Examining lives in context: Perspectives on the ecology of human development (pp. 101-139). Washington: APA Press. doi: https://doi.org/10.1037/10176-003

Fine, M., \& Weis, L. (2000). Disappearing acts: The state and violence against women in the twentieth century. Signs, 25, 1139-1146. doi: https://doi.org/10.1086/495534

Gjertson, L. (2011). Summary of workshop proceedings: Exploring the intersection between financial capability and domestic violence. Center for Financial Security, University of Wisconsin: Madison WI.

Gondolf, E. W., \& Williams, O. J. (2001). Culturally focused batterer counseling for African American men. Trauma, Violence, \& Abuse, 2, 283-295. doi: https://doi.org/10.1177/1524838001002004001

Hahn, S. A., \& Postmus, J. L. (2014). Economic empowerment of impoverished IPV survivors: A review of best practice literature and implications for policy. Trauma, Violence, \& Abuse, 15(2), 79-93. doi: https://doi.org/10.1177/1524838013511541

Haynes, K. (1998). The one hundred-year debate: Social reform versus individual treatment. Social Work, 43(6), 501-509. doi: https://doi.org/10.1093/sw/43.6.501

Hawkins, R. L., \& Kim, E. J. (2012). The socio-economic empowerment assessment: Addressing poverty and economic distress in clients. Clinical Social Work Journal, 40, 194-202. doi: https://doi.org/10.1007/s10615-011-0335-4

Johnson, M. E. (2015). Changing course in the anti-domestic violence legal movement: From safety to security. Villanova Law Review, 60, 145-201. doi: https://doi.org/10.2139/ssrn.2579639

Jorgensen, M., \& Morris, P. (2010). Tribal experience with children's accounts. Children and Youth Services Review, 32, 1528-1537. doi: https://doi.org/10.1016/j.childyouth.2010.03.017

Kyriakakis, S., Dawson, B.A, \& Edmond, T. (2012). Mexican immigrant survivors of intimate partner violence: Conceptualization and descriptions of abuse. Violence and Victims, 27(4), 548-562. doi: https://doi.org/10.1891/0886-6708.27.4.548

Lindhorst, T., \& Padgett, J. (2005). Disjunctures for women and frontline workers: Implementation of the Family Violence Option. Social Service Review, 79(3), 405429. doi: https://doi.org/10.1086/430891 
McCue, M. L. (2007). Domestic violence: A reference handbook ( $2^{\text {nd }}$ ed.). Santa Barbara, CA: ABC-CLIO, Inc.

McEachern, D., Van Winkle, M., \& Steiner, S. (1998). Domestic violence among the Navajo: A legacy of colonization. Journal of Poverty, 2(4), 31-46. doi:

https://doi.org/10.1300/J134v02n04 03

McGrath, M. (2015). A global financial literacy test finds that just $57 \%$ of adults in the U.S. are financially literate. Forbes. Available at http://www.forbes.com/sites/maggiemcgrath/2015/11/18/in-a-global-test-offinancial-literacy-the-u-s/\#140981366a16

Mickelson, K. D., \& Hazlett, E. (2014). Why me? Low-income women's poverty attributions, mental health, and social class perceptions. Sex Roles, 71, 319-332. doi: https://doi.org/10.1007/s11199-014-0414-4

Murphy-Erby, Y., Christy-McMullin, K., Stauss, K., \& Schriver, J. (2010). Multi-systems life course: A new practice perspective and its application in advanced practice with racial and ethnic populations. Journal of Human Behavior in the Social Environment, 20(5), 1-16. doi: https://doi.org/10.1080/10911351003751868

Murphy-Erby, Y., Jordan, S., Shobe, M., \& Christy-McMullin, K. (2009). Individual development accounts and social justice. Forum on Public Policy: A Journal of Oxford Roundtable, 2009(1). Available at

https://www.researchgate.net/publication/237390022_Individual_Development_Acco unts and Social Justice

National Center on Domestic and Sexual Violence [NCDSV]. (2017). National center on domestic and sexual violence: Training, consulting, advocacy. Available at http://www.ncdsv.org/images/Teen\%20P\&C\%20wheel\%20NO\%20SHADING.pdf

National Coalition Against Domestic Violence [NCADV]. (2015). Domestic violence national statistics. Available at http://ncadv.org/images/Domestic\%20Violence.pdf

National Women's Law Center. (2016). The wage gap: The who, how, why, and what to do. Washington D. C. Retrieved from https://nwlc.org/wpcontent/uploads/2016/09/The-Wage-Gap-The-Who-How-Why-and-What-to-Do.pdf

Outlaw, M. (2009). No one type of intimate partner abuse: Exploring physical and nonphysical abuse among intimate partners. Journal of Family Violence, 24(4), 263-272. doi: https://doi.org/10.1007/s10896-009-9228-5

Page-Adams, D., \& Sherraden, M. (1997). Asset building as a community revitalization strategy. Social Work, 42(5), 423-434. doi: https://doi.org/10.1093/sw/42.5.423

Page-Reeves, J. (2011). Commentary: The nexus of poverty, hunger, and homelessness in New Mexico. Social Justice, 38(3), 33-41.

Personal Responsibility and Work Opportunity Reconciliation Act of 1996, Pub. L. 104193, 110 Stat. 2105, codified as amended at 42 U.S.C. $\S \S 1305$. 
Peterson, R. (1980). Social class, social learning and wife abuse. Social Service Review, 54, 390-406. doi: https://doi.org/10.1086/643846

Postmus, J. L. (2011). Understanding financial literacy with survivors of intimate partner violence [CFS Research Brief 2011-5.2]. Retrieved from https://pdfs.semanticscholar.org/b5ff/7d485cf6e6f7a2b0d80d800b8ba0c9ced404.pdf

Postmus, J. L., Plummer, S., McMahon, S., Murshid, N. S., \& Kim, M. S. (2012). Understanding economic abuse in the lives of survivors. Journal of Interpersonal Violence, 27(3), 411-430. doi: https://doi.org/10.1177/0886260511421669

Purtell, K., \& McLoyd, V. (2013). A longitudinal investigation of employment among low-income youth: Patterns, predictors, and correlates. Youth \& Society, 45(2), $243-$ 264. doi: https://doi.org/10.1177/0044118X11416019

Pyles, L. (2006). Economic well-being and intimate partner violence: New findings about the informal economy. Journal of Sociology \& Social Welfare, 33(3), 101-126.

Rennison, C., \& Planty, M. (2003). Non-lethal intimate partner violence: Examining race, gender, and income patterns. Violence and Victims, 18(4), 433-443. doi: https://doi.org/10.1891/vivi.2003.18.4.433

Renzetti, C. (1998) Violence and abuse in lesbian relationships: Theoretical and empirical issues. In R.K. Bergen (Ed.). Issues of intimate violence (pp. 117-125). Thousand Oaks, CA: Sage. doi: http://dx.doi.org/104135/9781483328348.n7

Richie, B. (2000). A black feminist reflection on the antiviolence movement. Signs, 25, 1133-1137. doi: https://doi.org/10.1086/495533

Richie, B., \& Kanuha, V. (1993). Battered women of color in public health care systems: Racism, sexism, and violence. In B. Bair \& S. E. Cayleff (Eds.), Wings of gauze: Women of color and the experience of health and illness (pp. 288-299). Detroit, MI: Wayne State University.

Sanders, C. (2011). Facilitating savings and asset ownership among domestic violence survivors. Center for Financial Security, University of Wisconsin. CFS Research Brief 2011-5.3.

Sanders, C. (2014). Savings for survivors: An Individual Development Account program for survivors of intimate-partner violence. Journal of Social Service Research, 40(3), 297-312. doi: https://doi.org/10.1080/01488376.2014.893950

Sanders, C. (2015). Economic abuse in the lives of women abused by an intimate partner: A qualitative study. Violence Against Women, 21(1), 3-29. doi: https://doi.org/10.1177/1077801214564167

Sanders, C. \& Schnabel, M. (2008). Organizing for economic empowerment of battered women: Women's Savings Accounts. Journal of Community Practice, 14(3), 47-68. doi: http://dx.doi.org/10.1300/j125v14n03 04 
Schrag, R. V. (2015). Economic abuse and later material hardship: Is depression a mediator? Affilia: Journal of Women \& Social Work, 30(3), 341-351. doi: https://doi.org/10.1177/0886109914541118

Sherraden, M. (1988). Rethinking social welfare: Toward assets. Social Policy, 18(3), $37-$ 43.

Sherraden, M. (1991). Assets and the poor: A new American welfare policy. Armonk, NY: M.E. Sharpe.

Sokoloff, N.J., \& Dupont, I. (2005). Domestic violence at the intersections of race, class, and gender. Violence Against Women, 11(1), 38-64. doi:

https://doi.org/10.1177/1077801204271476

Standard and Poor. (2015). Financial literacy in the United States. Available at https://media.mhfi.com/documents/SandP US FINAL.pdf

The Family Violence Option of 1996, Pub. L. 104-193, 110 Stat. 2105, codified as amended at 42 U.S.C. $\S \S 1305$.

The NW Network. (n.d.). The NW Network of Bi, Trans, Lesbian and Gay Survivors of Abuse. Available at https://static1.squarespace.com/static/566c7f0c2399a3bdabb57553/t/582b7f6e440243 e4d6d05c67/1479245679835/11-Power-and-Control-Wheel-for-LGBT.pdf

Trygged, S., Hedlund, E., \& Käreholt, I. (2014). Beaten and poor? A study of the longterm economic situation of women victims of severe violence. Social Work in Public Health, 29, 100-113. doi: https://doi.org/10.1080/19371918.2013.776320

Valandra. (2007). Reclaiming their lives and breaking free: An Afrocentric approach to recovery from prostitution. Afflia: Journal of Women and Social Work, 22(2), 195208. doi: https://doi.org/10.1177/0886109907299052

Valandra, Murphy-Erby, Y., Higgins, M., \& Brown, L. (2016). African American perspectives and experiences of domestic violence in a rural community. Journal of Interpersonal Violence, 2016, 1-25. doi: https://doi.org/10.1177/0886260516669542

Violence Against Women Act of 1994, Pub. L. 103-322, 108 Stat. 1796, codified as amended at 42 U.S.C. $\S \S 13701-14040$.

Vitt, L. A., Anderson, C., Kent, J., Lyter, D. M., Siegenthaler, J. K., \& Ward, J. (2000). Personal finance and the rush to competence: Financial literacy education in the U.S. Middleburg, VA: Institute for Socio-Financial Studies.

Weaver, T., Sanders, C., Campbell C., \& Schnabel, M. (2009). Development and preliminary psychometric evaluation of the Domestic Violence-related Financial Issues Scale (DV-FI). Journal of Interpersonal Violence, 24(4), 569-585. doi: https://doi.org/10.1177/0886260508317176

West, T. (1999). Wounds of the spirit: Black women, violence, and resistance ethics. New York: New York University Press. 
Author note: Address correspondence to: Kameri Christy, School of Social Work, University of Arkansas, SCSW 104B, Fayetteville, AR 72701-1201, 491-575-4655, kameric@uark.edu 